\title{
Influence of Dynamic Load on Soil Moisture Field in the Process of Freeze-Thaw Cycles
}

\author{
Yongting Huang, ${ }^{1,2}$ Wei Ma $\mathbb{D}^{1,2}$ Donghui Xiao, ${ }^{3}$ and Yuezhen $\mathrm{Xu}^{1,2}$ \\ ${ }^{1}$ State Key Laboratory of Frozen Soil Engineering, Northwest Institute of Eco-Environment and Resources, \\ Chinese Academy of Sciences, Lanzhou, Gansu 730000, China \\ ${ }^{2}$ University of Chinese Academy of Science, Beijing 100049, China \\ ${ }^{3}$ Poly Changda Engineering Company Limited, Guangzhou, Guangdong 510000, China \\ Correspondence should be addressed to Wei Ma; mawei@lzb.ac.cn
}

Received 1 March 2021; Accepted 3 June 2021; Published 22 December 2021

Academic Editor: Xiao Dong Zhao

Copyright (c) 2021 Yongting Huang et al. This is an open access article distributed under the Creative Commons Attribution License, which permits unrestricted use, distribution, and reproduction in any medium, provided the original work is properly cited.

\begin{abstract}
Due to climate warming and large-scale engineering activities, the embankment engineering risk in the permafrost and seasonally frozen regions caused by water content change in the soil has become more and more serious. To study the moisture migration law in the embankment under the vehicle load action and periodic variation of temperature, a series of temperature-controlled model tests under the dynamic load condition were carried out, the dynamic load was imposed by an air hammer connecting a vibration plate, which was installed on the top surface of the soil, and the variation law of the temperature and moisture fields in the model was analyzed. The test results show that the moisture field in the soil sample changes obviously with the increasing freeze-thaw cycles under the no-load condition, especially after nine freeze-thaw cycles, two moisture accumulation areas appear in the range of $8-15 \mathrm{~cm}$ from the soil surface; the dynamic load has an inhibitory effect on the moisture migration within $5 \mathrm{~cm}$ below the vibration plate and has a promoting effect on the range of $10-30 \mathrm{~cm}$ below the vibration plate. With the increase in the number of freeze-thaw cycles, three high-water content areas are gradually formed and approximately uniformly distributed within the 10-25 cm depth range of the soil, which has an important impact on the stability of the soil. The water content of the moisture accumulation areas during freezing is greater than that during thawing under the no-load condition, while the water content of the moisture accumulation areas during freezing is less than that during thawing under dynamic load. The research results can provide references for the embankment design and disease treatment in cold regions.
\end{abstract}

\section{Introduction}

In cold regions, the land surface will undergo repeated freezing and thawing due to periodic fluctuations in surface temperature [1]. As a process of intense weathering, the freeze-thaw cycle strongly changes the physical and mechanical properties of the soil, such as particle size, internal structure, and pore water distribution of the soil, which affects the stability of the engineering structure [2-6]. In the seasonally frozen regions, the freeze-thaw cycle causes repeated frost heave and thaw settlement of the surface soil, which is a crucial reason for engineering and natural diseases [7]. Frost heave and thaw settlement are closely related to the variation of moisture in the soil. During freezing, the moisture in the unfrozen area will migrate to the freezing front due to the thermal gradient and other driving forces. During thawing, the moisture flows down under the selfweight. However, the moisture cannot return to the original position after freezing and thawing due to some retarding force of soil particles, making the moisture redistribute $[3,8-10]$.

Konrad and Morgenstern [11] and Gilpin [12] studied moisture migration law in the soil through experiments. They found that the variation of the initial water content and temperature gradient are critical reasons for moisture migration in unsaturated soils. Hanks [13] conducted experiments on the moisture vapor migration in three sandy soils and found that the moisture vapor migration conforms to 
the simple diffusion theory. Chen and Liu [14] conducted many laboratory experiments to study the influence of different factors on moisture migration. The results showed that the moisture migration in frozen soil is related to the soil-water potential gradient, which is influenced by many parameters, such as physical and mechanical properties of the soil, test boundary conditions, freezing speed, temperature gradient, and other parameters. Zhang et al. [15] carried out large-scale laboratory model tests of moisture migration and explored the influence of soil density, freezing temperature, water content, freezing method, and other factors on the moisture migration of unsaturated soil, but they did not consider the influence of temperature gradient on moisture migration in the soil. Lu et al. [16] studied the variation of unfrozen water content and temperature of Qinghai-Tibet Plateau silty clay with different initial water content. The results showed that the supercooling phenomenon during the freeze-thaw process was strengthened significantly with the increase in initial water content of the soil samples, and the freezing rate was greatly increased. Wei et al. [17] conducted the freezing test of saturated soil under different temperature boundaries and sample heights. The results showed that freezing rate and frost heaving ratio were inversely proportional to the height of the soil sample and directly proportional to the temperature gradient.

The moisture migration rate for different soils is different, and the moisture migration rate decreases with the increase in dry density for the same soil [18]. Wang and Lu [19] studied the moisture migration of unsaturated soil under different temperature gradients. The results showed that the variation of the water content has a more significant correlation with the temperature gradient size and the dry density, and the water content of the soil near the warm end of the specimen decreased, while the water content of the soil near the cold end showed an increasing trend. Huang et al. [20] studied the frost heaving and deformation process of frozen soil under external loads. The results show that the external load has a great influence on the driving force of moisture migration, which causes changes in the amount of moisture migration, migration rate, and frost heaving ratio. Zhao et al. [21, 22] analyzed the moisture migration in soil samples under different freezing temperatures and thawing temperatures. The results showed that different freezing and thawing temperatures significantly affect the moisture migration in the soil samples, and the higher the freezing temperature of the top board of the test cases, the more the water content accumulation at the water accumulation layer. Zhang et al. [23] analyzed the moisture migration during the freeze-thaw cycle for sandy soil and silty clay and concluded that the water supply rate of silty clay is greater than that of sandy soil during the freeze-thaw cycle.

In seasonally frozen regions, the moisture in the embankment migrates during the freeze-thaw process. During freezing, the moisture migrates from the position with the high potential energy of the soil to the position with low potential energy, and the moisture near the frozen fringe migrates to the freezing front; during thawing, the moisture in the thawed area migrates to the frozen area. Therefore, the freeze-thaw cycle causes repeated moisture migration in the embankment, which results in moisture accumulation and changes the internal structure of the soil, thus changing the mechanical characteristics of the soil and leading to a decrease in the stability of the embankment [24]. When the moisture accumulates to a certain extent, the embankment will be damaged due to more significant frost heaving action during freezing. At the same time, under the combined actions of the vehicles and other upper loads, the road with excessively high-water content during thawing will produce pavement overturning and other phenomena, which has a huge impact on the performance and service life cycle of the roads [25]. This shows that moisture migration during the freeze-thaw cycle is highly crucial to the deformation of the soil and the stability of the embankment. However, the current research on moisture migration is mainly focused on model tests and small soil sample tests under unloaded conditions and few reports studies have been reported the influence of dynamic loads and freeze-thaw cycles on soil moisture migration based on large model tests. Therefore, this article carries out model tests under dynamic load and freeze-thaw cycles, measures the temperature and moisture in the soil during the tests, and analyses the moisture migration mechanism under dynamic loads. The research results can provide a scientific basis for the design, construction, and disease treatment of the embankment projects in seasonally frozen regions.

\section{Experiment Materials and Methods}

2.1. Soil Samples. The soil used in this model test is Lanzhou loess in Gansu Province $\left(36^{\circ} 01^{\prime} 14^{\prime \prime} \mathrm{N} 103^{\circ} 50^{\prime} 15^{\prime \prime} \mathrm{E}\right.$, altitude $1624 \mathrm{~m}$ ), which belongs to the temperate continental climate and seasonal frozen regions [9]. The physical properties of the soil such as initial water content, natural dry density, specific gravity of soil particles, liquid limit, and plastic limit are tested according to the Standard for Geotechnical Testing Method, and results are shown in Table 1 [26]. Figure 1 shows the grain-size diameter distribution obtained by the laser diffraction method. The plasticity index of the soil is 8.6 less than 10 , and the liquid limit of the soil is $27.3 \%$ less than $50 \%$, so the soil is designated as a low liquid limit silt soil.

2.2. Model Testing Apparatus. The model test was carried out by a small temperature-controlled environmental chamber in the State Key Laboratory of Frozen Soil Engineering of the Chinese Academy of Sciences (Figure 2) [27]. The model test system includes an environmental chamber, a temperature control system, an insulation test chamber, a water supplement system, a vibration system, and an observation system (Figure 3 ). The internal space size of the environmental chamber is $1 \mathrm{~m} \times 1 \mathrm{~m} \times 1 \mathrm{~m}$, and its internal temperature is controlled by the temperature control system. The temperature control system is mainly composed of the compressor, the temperature controller, the liquid crystal control panel, the Freon liquid circulation pipeline, the evaporator, and the temperature sensor. The temperature control process is manually set on the liquid crystal control panel and automatically controlled by the instrument. The 
TABLE 1: The physical properties of the soil.

\begin{tabular}{lcccccc}
\hline Parameters & $\begin{array}{c}\text { Initial water content } \\
(\%)\end{array}$ & $\begin{array}{c}\text { Natural dry density } \\
\left(\mathrm{g} \cdot \mathrm{cm}^{-3}\right)\end{array}$ & $\begin{array}{c}\text { Particle density } \\
\left(\mathrm{g} \cdot \mathrm{cm}^{-3}\right)\end{array}$ & $\begin{array}{c}\text { Plastic limit } \\
(\%)\end{array}$ & $\begin{array}{c}\text { Liquid limit } \\
(\%)\end{array}$ & $\begin{array}{c}\text { Plasticity index } \\
\text { Test value }\end{array}$ \\
\hline
\end{tabular}

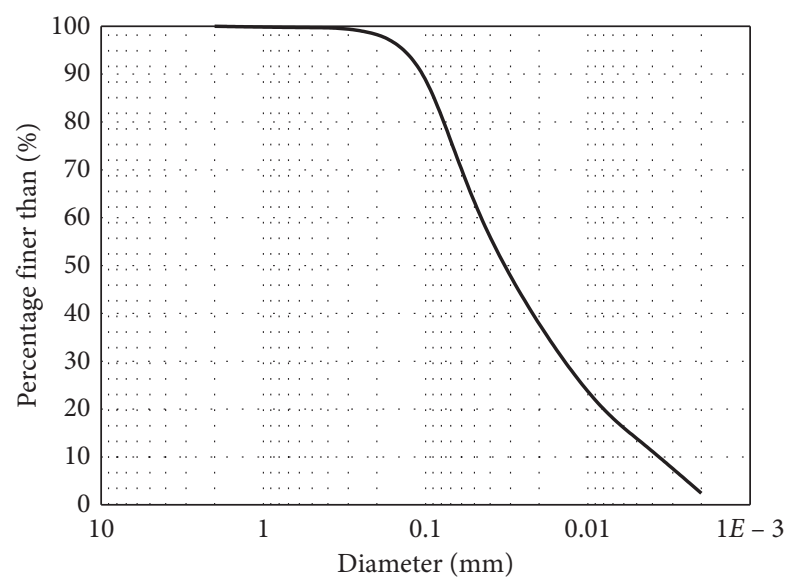

FIgURE 1: The grain-size diameter distribution.

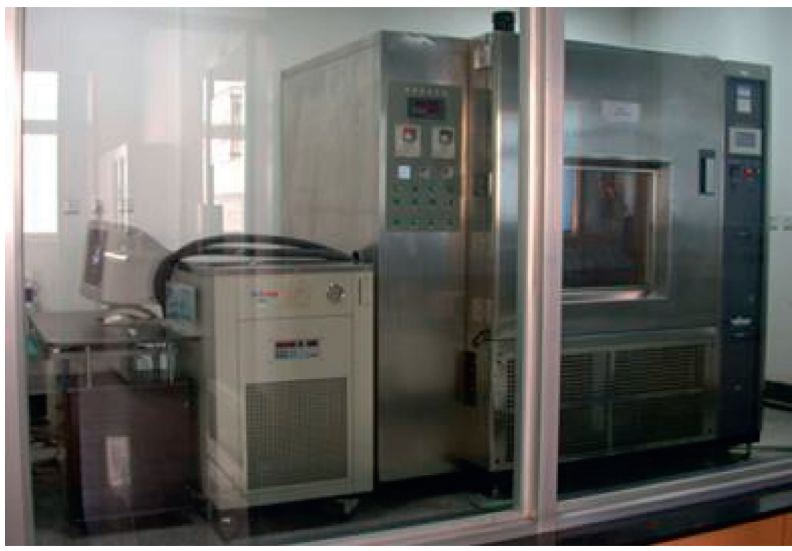

Figure 2: Temperature-controlled environmental chamber.

temperature control range of the system is from $-40^{\circ} \mathrm{C}$ to $+100^{\circ} \mathrm{C}$, and the temperature accuracy is about $\pm 0.3^{\circ} \mathrm{C}$. The insulation test chamber is used to fill the soil, and its internal dimension is $0.7 \mathrm{~m} \times 0.7 \mathrm{~m} \times 0.4 \mathrm{~m}$. The insulation test chamber is placed in the environmental chamber, and its wall is made of insulation materials to ensure one-dimensional freezing and thawing of soil samples. The water supplement system mainly provides a water supply source for the soil in the insulation test chamber, which is equivalent to the groundwater level. The bottom water supplement system consists of a water inlet, water bin, and drainage port. The water inlet is located at the bottom of the side of the water bin, and the drainage port is located at the top of the side of the water bin, the purpose of which is to ensure that the water enters from the bottom up and gradually fills up the water bin. The vibration system consists of a vibration plate, air hammer, solenoid valve, relay, and air compressor. The vibration frequency of the dynamic load is mainly controlled by the air hammer fixed on the vibration plate; the maximum impact force of the air hammer is $9.6 \mathrm{~kg} \cdot \mathrm{m} \cdot \mathrm{s}^{-1}$. The vibrating plate is a square of $0.18 \times 0.18 \mathrm{~m}$, and the total mass of the vibrating plate, inner ring sleeve, and air hammer is about $16.2 \mathrm{~kg}$. The observation system mainly consists of thermal sensors, moisture sensors, and a data acquisition instrument. The moisture sensors choose EC-5 soil moisture sensors (Figure 4), the range is $0 \sim 100 \%$, and the accuracy is $\pm 3 \%$; the data are collected by the CR3000 data acquisition instrument.

2.3. Experiment Design. To study the influence of dynamic load on the moisture and temperature field in the soil, two model tests were designed: one is under the no-load condition on the sample surface and the other is to apply dynamic load on the sample surface. The vibration frequency of the dynamic load is $0.164 \mathrm{~Hz}$, which is selected according to 


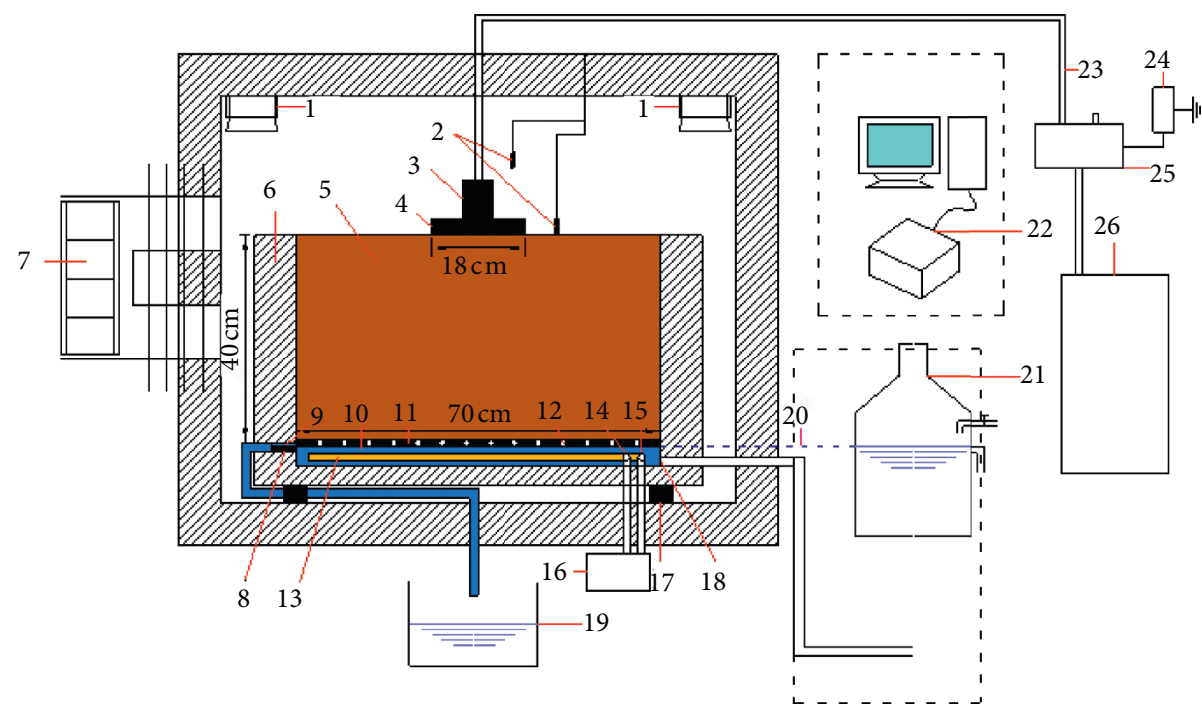

1 Cooling fan
2 Thermistors
3 Air hammer
4 Vibrating bottom plate
5 Soil sample
6 Insulation materimal
7 Compressor
8 Cork
9 Drain
10 Water supplement cabin

11 Bottom plate

12 Water supplement hole

13 Copper pipe

14 Copper pipe inlet

15 Copper pipe outlet

16 Cryostat

17 The base

18 Water inlet

19 Drainage system

20 Water level line

Figure 3: System of the modelling test: 1: cooling fan, 2: thermistors, 3: air hammer, 4: vibrating bottom plate, 5: soil sample, 6: insulation material, 7: compressor, 8: cork, 9: drain, 10: water supplement cabin, 11: bottom plate, 12: water supplement plate, 13: copper pipe, 14: copper pipe inlet, 15: copper pipe outlet, 16: cryostat, 17: the base, 18: water inlet, 19: draining system, 20: water level inline, 21: water supply system, 22: data acquisition system, 23: intake pipe, 24: relay, 25: solenoid wave, and 26: air compressor.

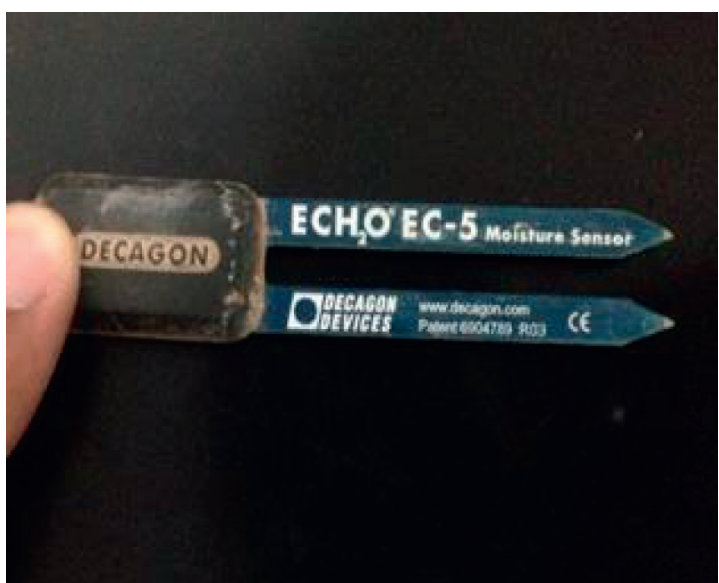

Figure 4: EC-5 soil moisture sensors.

the high-speed traffic flow $[28,29]$. The loading time is $0.4 \mathrm{~s}$, the unloading time is $5.7 \mathrm{~s}$, and the specific loading method is shown in Figure 5. The boundary temperature is controlled by an environmental test chamber, and the temperature data are referenced to the monthly average temperature in the loess area of Lanzhou City, which varies between -8.06 and $15.7^{\circ} \mathrm{C}$ in a sinusoidal function curve, and

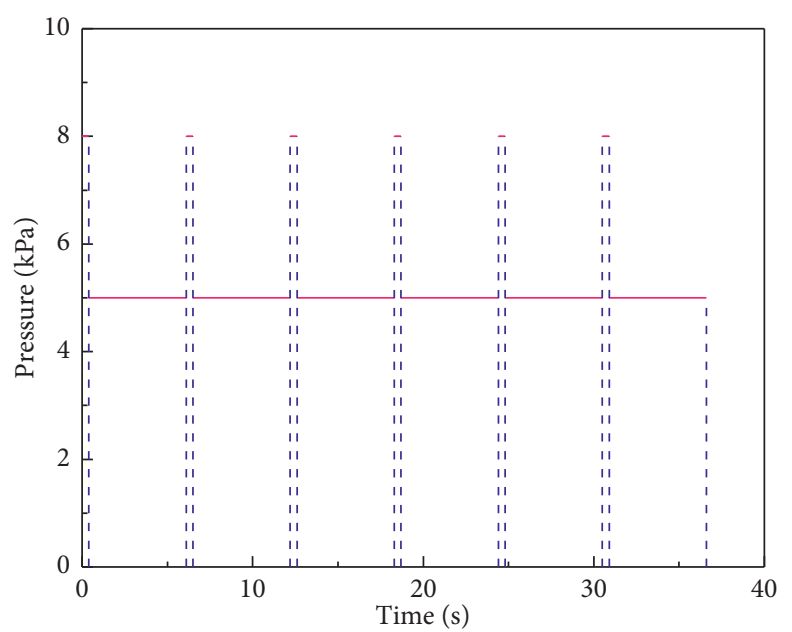

FIGURE 5: Dynamic load variations.

the freeze-thaw period is $24 \mathrm{~h}$. The fitted curve based on the measured values of temperature is shown in Figure 6, and the fitted temperature equation is expressed as follows:

$$
T=3.82+11.88 \times \sin \left(\frac{2 \pi t}{24}+\frac{\pi}{2}\right) \text {. }
$$




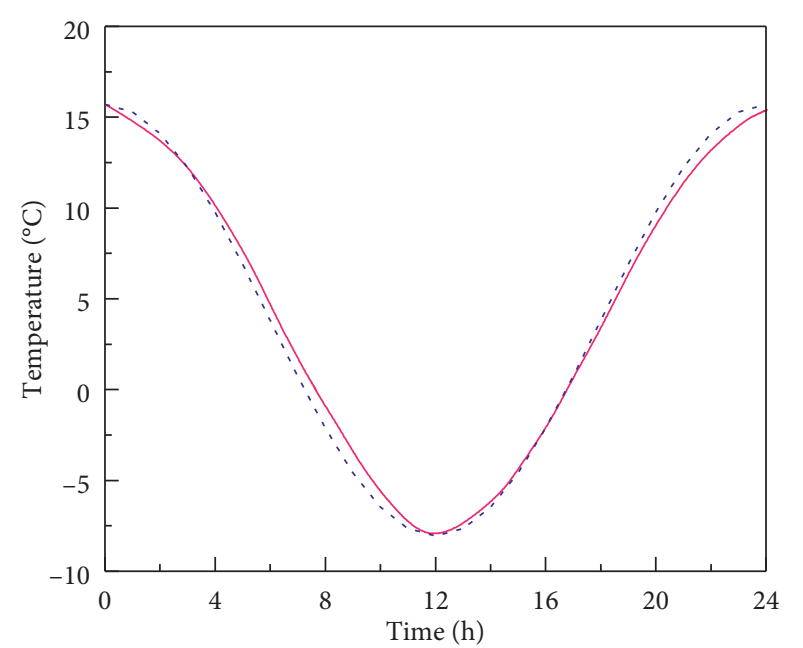

Boundary temperature

- Measured value

- - - Fitted value

FIgURE 6: The boundary temperature change curve.

The test process is as follows. (1) Soil. The air-dried soil was added to a certain amount of distilled water, mixed well, and passed through a $2 \mathrm{~mm}$ sieve. And then, the water content measured by the drying method is $10.6 \%$ after 24 hours of sealed storage. (2) Sample. The prepared soil is weighed and compacted in layers in the insulation test chamber. The dry density of the sample was controlled at $1.6 \mathrm{~g} \cdot \mathrm{cm}^{-3}$. After the soil sample is filled, a piece of plastic film was covered on the top of the soil sample to prevent the evaporation of water. (3) Temperature. The soil sample was kept at $20^{\circ} \mathrm{C}$ for at least $48 \mathrm{~h}$, the purpose of which is to achieve a uniformly distributed initial temperature field. Then, the temperature of the environmental chamber was set to a sinusoidal mode (Figure 6) so that the soil is subjected to freeze-thaw cycles and simultaneously applied a dynamic load on the surface of the soil sample, where the variation of the dynamic load is shown in Figure 5. (4) Testing. During the test process, the temperature and moisture fields in the soil sample are measured by the thermal and moisture sensors arranged in layers, as shown in Figure 7. The thermal and moisture sensors are installed in the left half and right half, respectively, because the soil sample configuration, temperature, and load boundary are symmetrical.

\section{Results and Analysis}

3.1. Temperature Field in the Sample. Figure 8 shows the variation of temperature with time at different depths of the center of the soil sample under the combined action of dynamic load and freeze-thaw cycles. It can be seen that the soil temperature at different locations shows periodical variation with the boundary temperature. The amplitude variation of the temperature in the soil tends to decrease with increasing depth due to the thermal loss when heat is conducted downward from the surface of the soil. The variation of temperature in the soil sample lags behind the soil surface due to the time effect of thermal conduction. It is

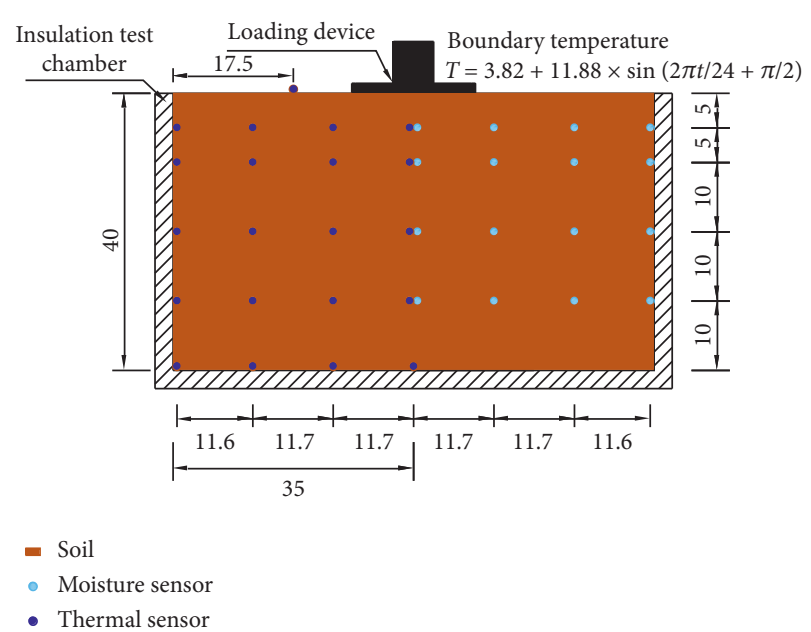

Figure 7: The location of moisture sensors and thermal sensors.

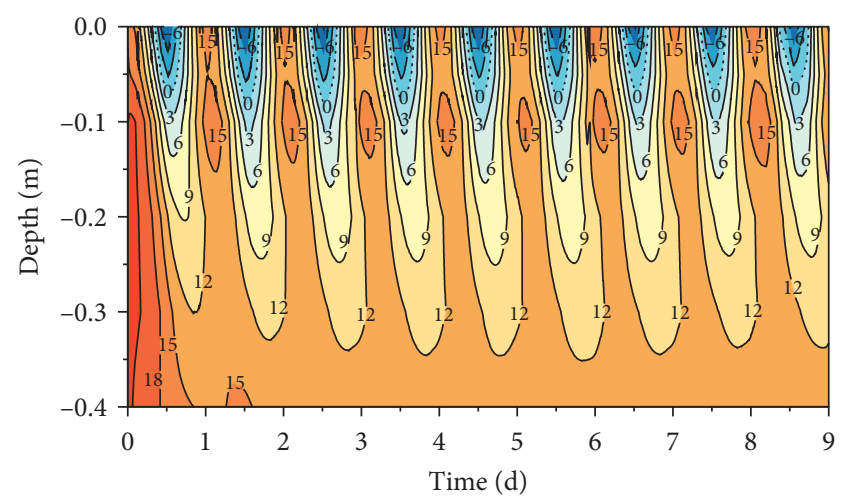

FIgURE 8: Variation of temperature in soil under dynamic load and freeze-thaw cycles.

also seen that the maximum temperature in the soil sample is about $16^{\circ} \mathrm{C}$, which occurs at the upper surface of the soil sample and a location of $10 \mathrm{~cm}$ from the upper surface of the soil during the freeze-thaw process, and the maximum depth of frost penetration is about $6.2 \mathrm{~cm}$ during the 1 st freezethaw cycle and about $8 \mathrm{~cm}$ after nine freeze-thaw cycles. This indicates that the cold capacity gradually accumulates in the soil sample.

Figure 9 shows the contour map of the temperature during the 1st, 5th, 9th, 12th, and 15th freeze-thaw cycles under dynamic loading where $1 \mathrm{~L}, 5 \mathrm{~L}, 9 \mathrm{~L}, 12 \mathrm{~L}$, and $15 \mathrm{~L}$ present the moments of the lowest ambient temperature (L) during the different freeze-thaw cycles $(1,5,9,15)$, and similarly $1 \mathrm{H}, 5 \mathrm{H}, 9 \mathrm{H}, 12 \mathrm{H}$, and $15 \mathrm{H}$ present the moments of the highest ambient temperature $(\mathrm{H})$ during the different freeze-thaw cycles $(1,5,9,12,15)$.

At the moment of the lowest ambient temperature during freeze-thaw cycles, the heat of soil is dissipated to the environment and the temperature of the soil sample gradually decreases and freezes from top to bottom. In the frozen area, the temperature of the soil sample under the vibration base plate is lower than that on both sides of the vibration plate at the same depth. Because the vibration base plate is 


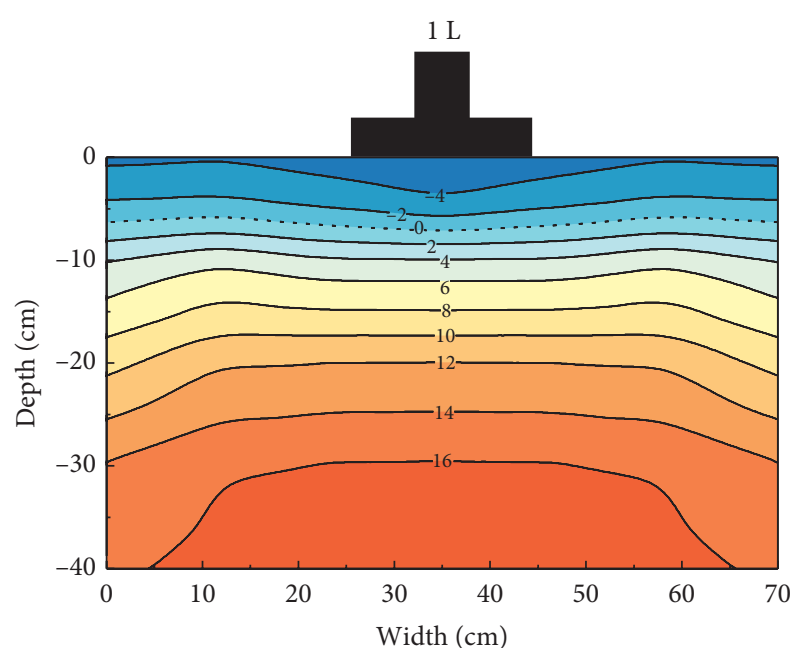

(a)

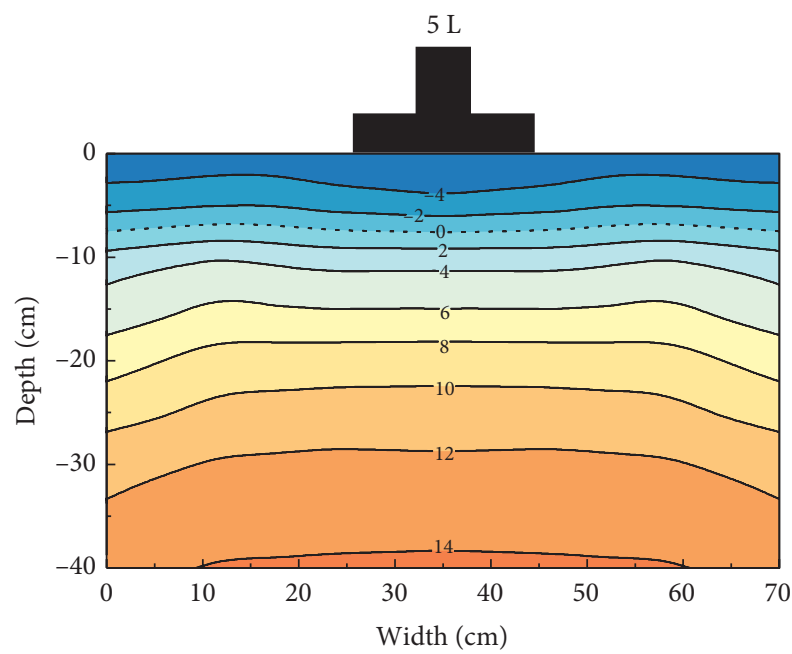

(c)

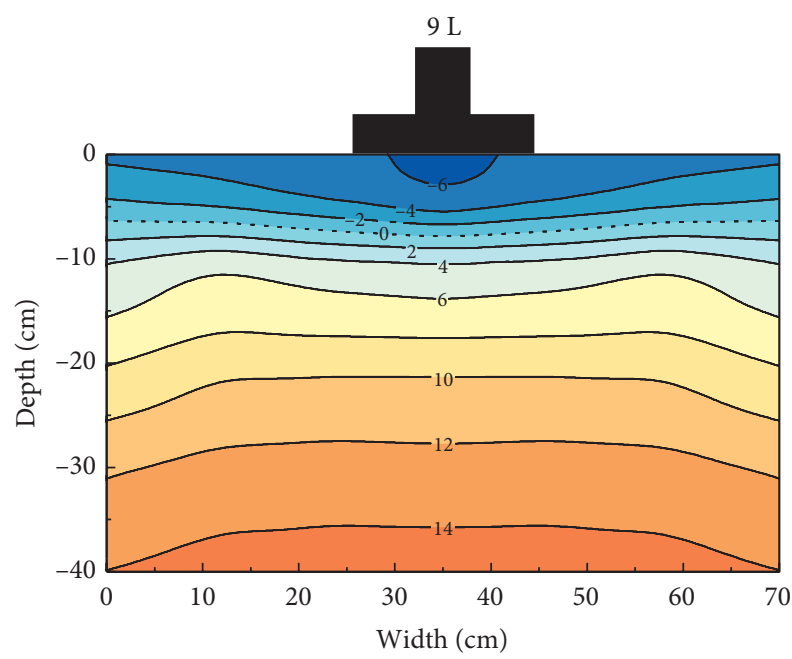

(e)

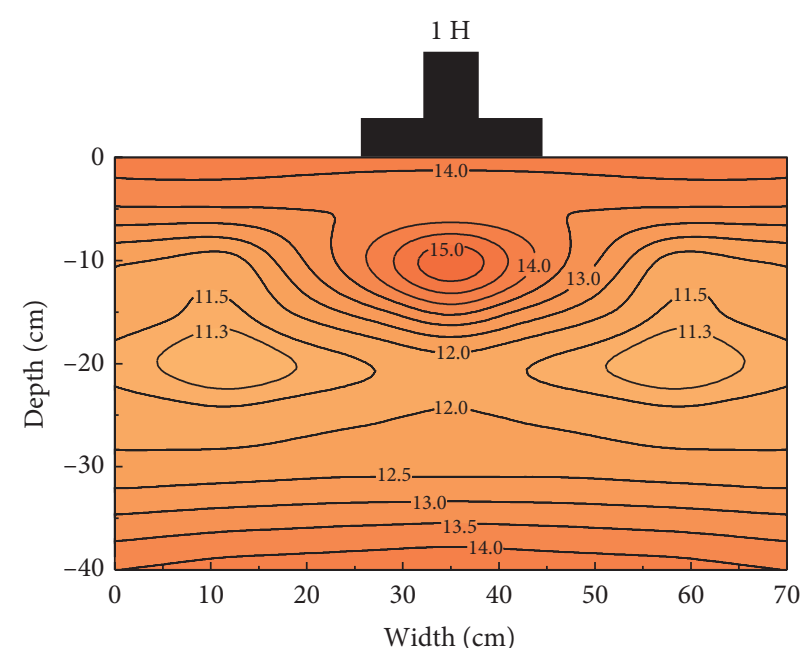

(b)

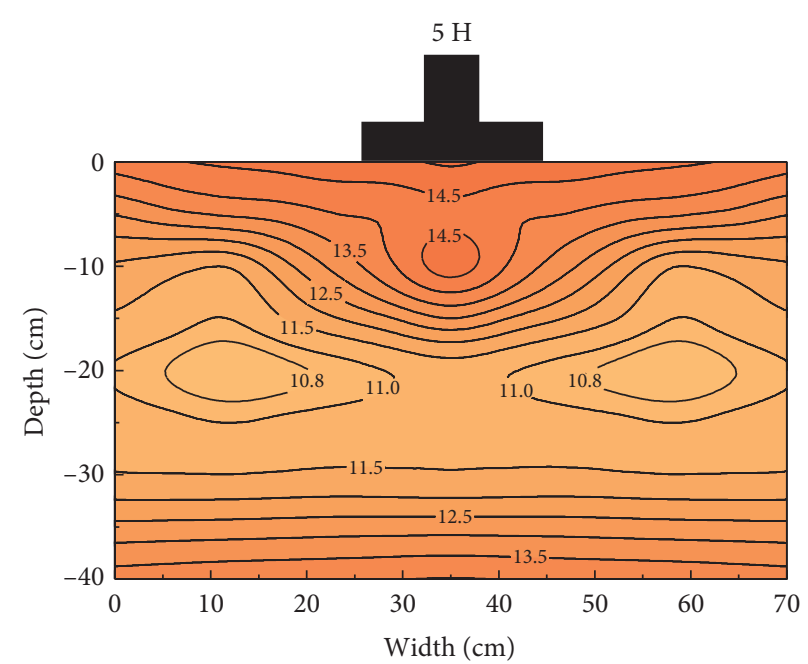

(d)

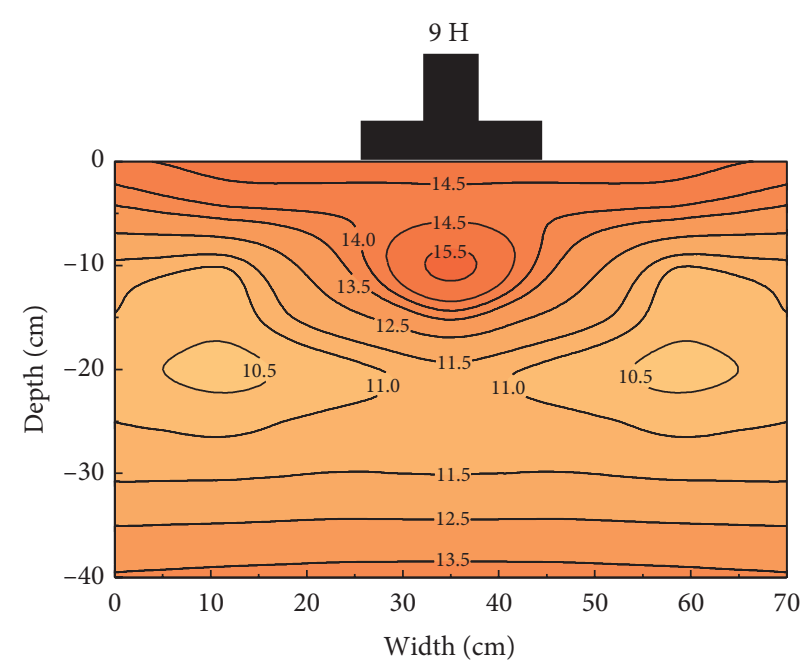

(f)

FIgURE 9: Continued. 


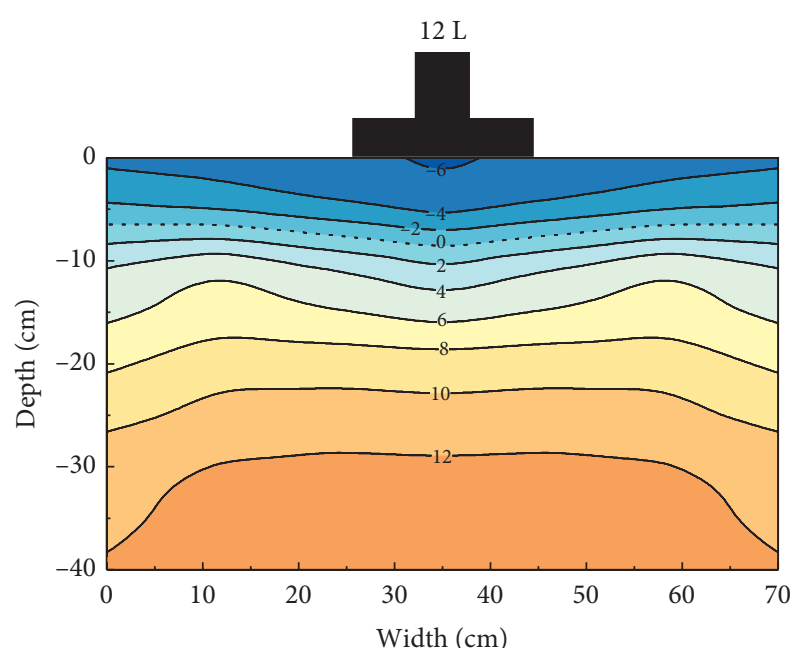

(g)

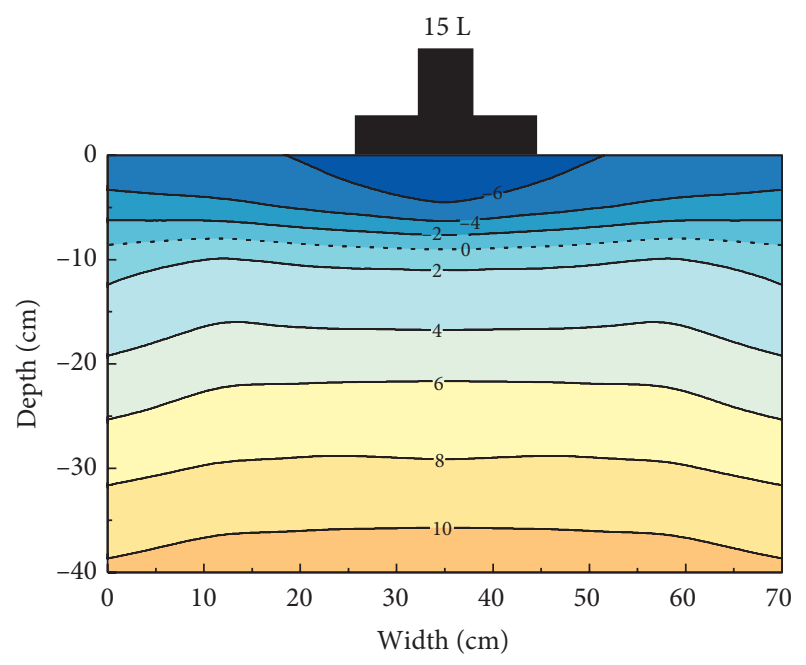

(i)

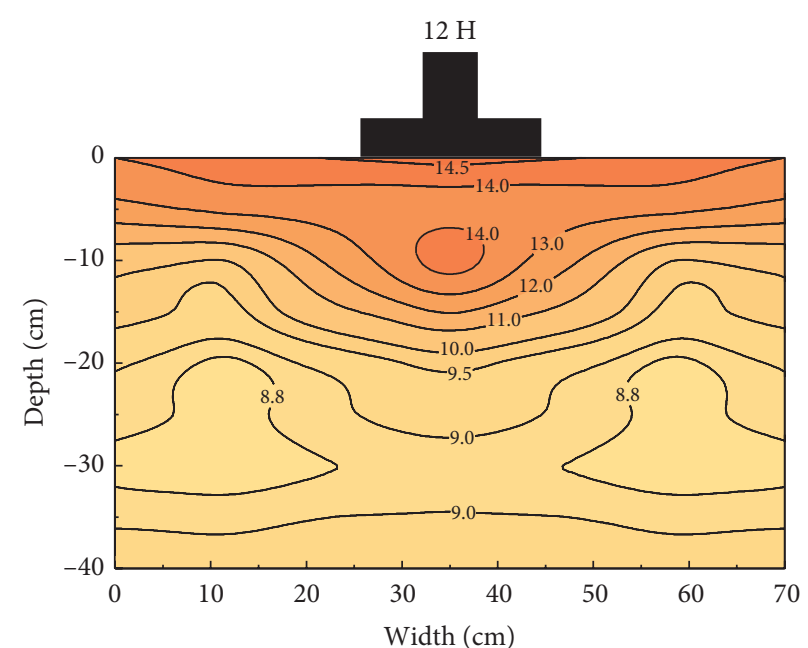

(h)

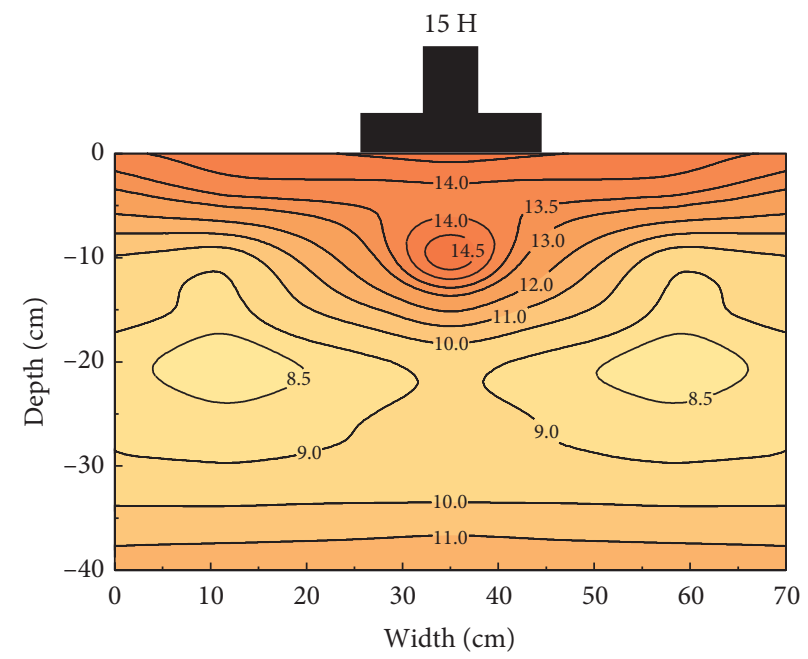

(j)

Figure 9: Variation of the temperature field at low and high temperature extremes at different freeze-thaw cycles.

made of steel with good thermal conductivity, which extrudes the soil surface during the loading process, thus it accelerates the release of heat from the surface soil to the environment, leading to the rate of temperature change of the soil under the vibration base plate greater than that on both sides. The results also show that the temperature under the vibration plate is gradually decreasing, and the lowtemperature area is gradually expanding with the increase in the freeze-thaw cycle. This indicates that the cold capacity of the soil sample is slowly accumulated during freeze-thaw cycles.

At the moment of the highest ambient temperature during freeze-thaw cycles, in the range of $0-20 \mathrm{~cm}$ from the soil surface, the temperature of the soil sample under the vibration base plate is greater than that on both sides of the plate at the same depth, which is also caused by the larger thermal conductivity of the vibration plate, and the temperature gap gradually increases with the increase in the number of freeze-thaw cycles (Figure 9). The reasons are that, on the one hand, the dynamic load accelerates the migration of moisture which further affects the distribution of the temperature field; on the other hand, the thermal conductivity of the vibration base plate is larger than soil and affects the heat transfer and accumulation of the soil sample. For example, at a depth of $10 \mathrm{~cm}$ from the soil surface and time of $1 \mathrm{H}$, the temperature at the center position is about $15.5^{\circ} \mathrm{C}$, at $11.7 \mathrm{~cm}$ from the center position is about $13.6^{\circ} \mathrm{C}$, and at $23.4 \mathrm{~cm}$ from the center position is about $11.8^{\circ} \mathrm{C}$. At the time of $15 \mathrm{H}$, the temperature at the center position is about $14.9^{\circ} \mathrm{C}$, at $11.7 \mathrm{~cm}$ from the center position is about $12.1^{\circ} \mathrm{C}$, and at $23.4 \mathrm{~cm}$ from the center position is about $9.4^{\circ} \mathrm{C}$. The temperature distribution is more uniform at locations below $20 \mathrm{~cm}$ from the soil surface. Moreover, the temperature decreases at each position of the sample with the increase in freeze-thaw cycles, which is caused by the accumulation of cold capacity in the soil sample during the freeze-thaw cycles.

For whole freeze-thaw cycles, the accumulation of cold capacity occurs in the soil regardless of whether the ambient temperature is low or high. That is because the thermal 


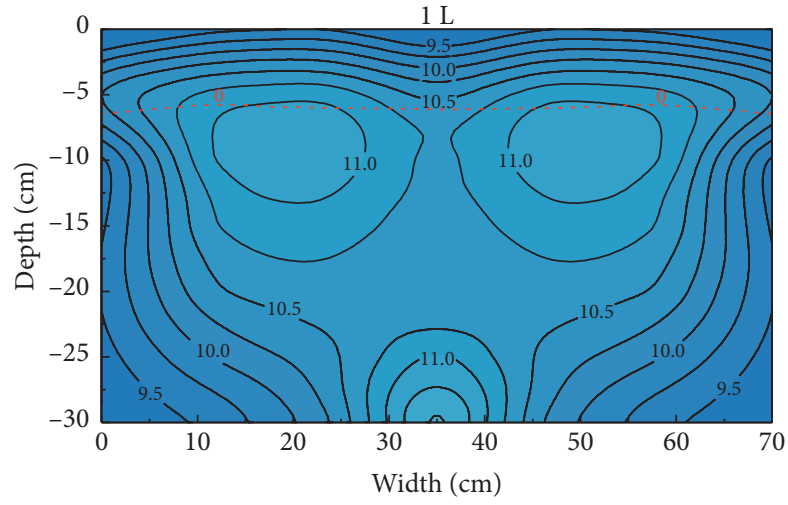

(a)

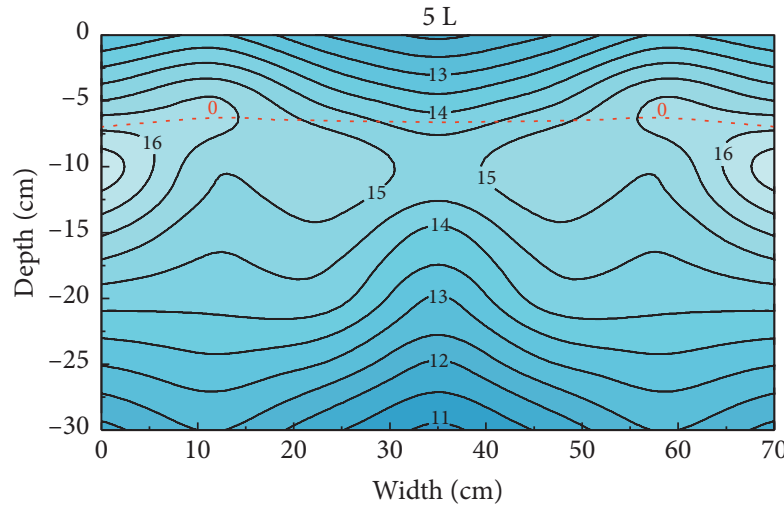

(c)

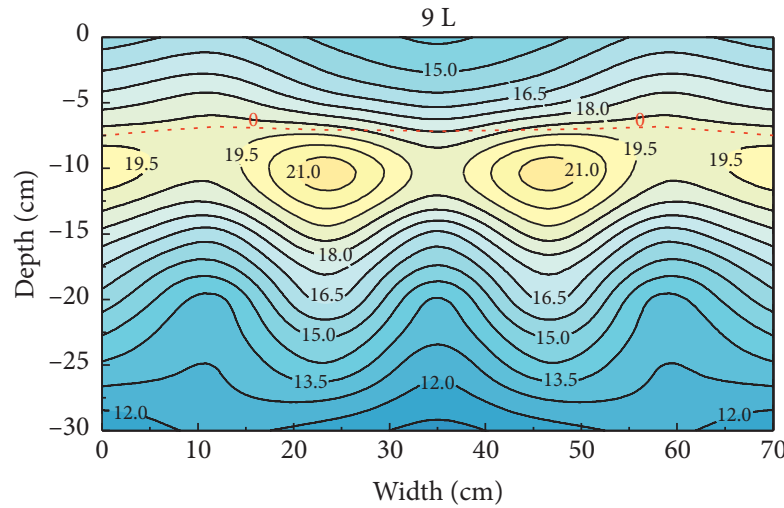

(e)

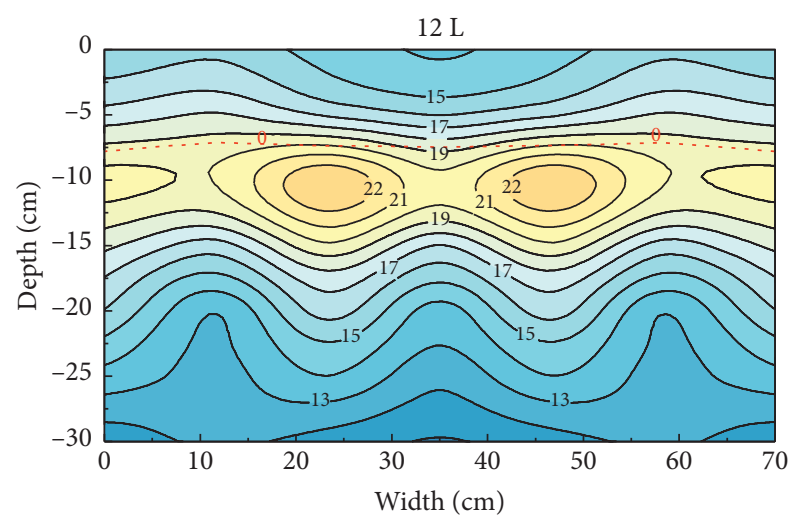

(g)

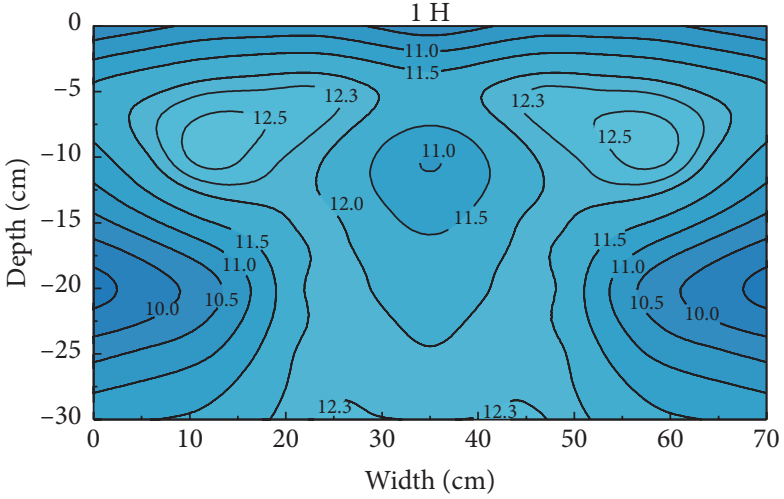

(b)

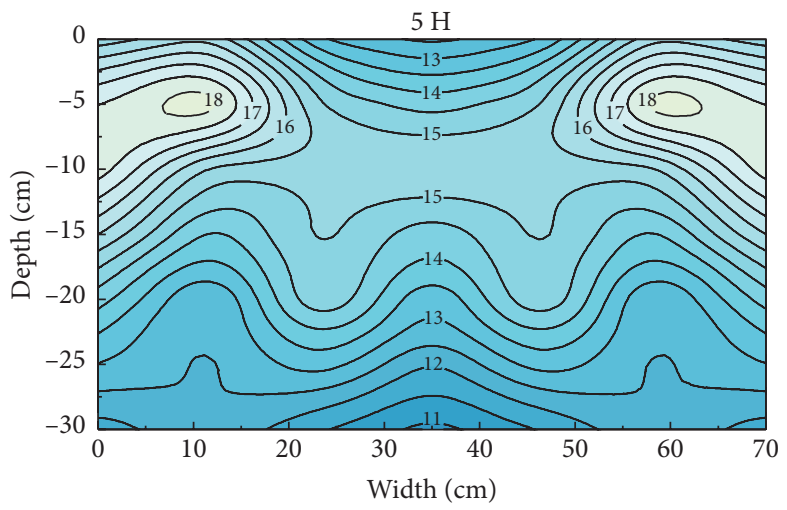

(d)

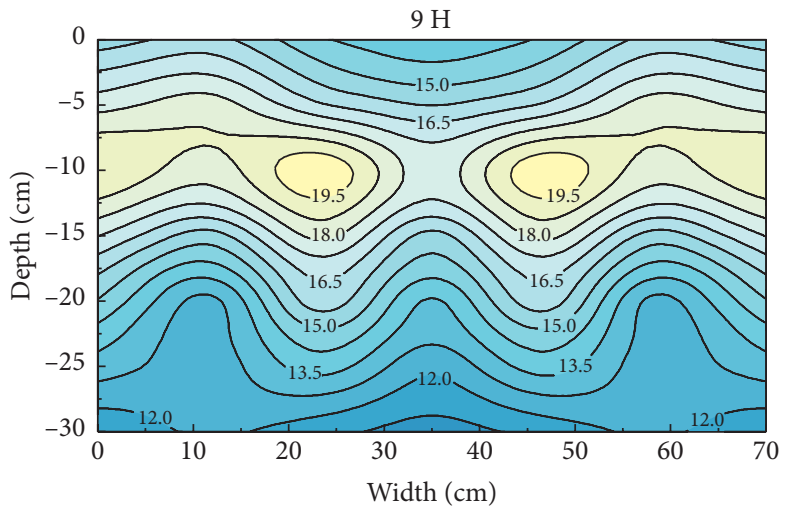

(f)

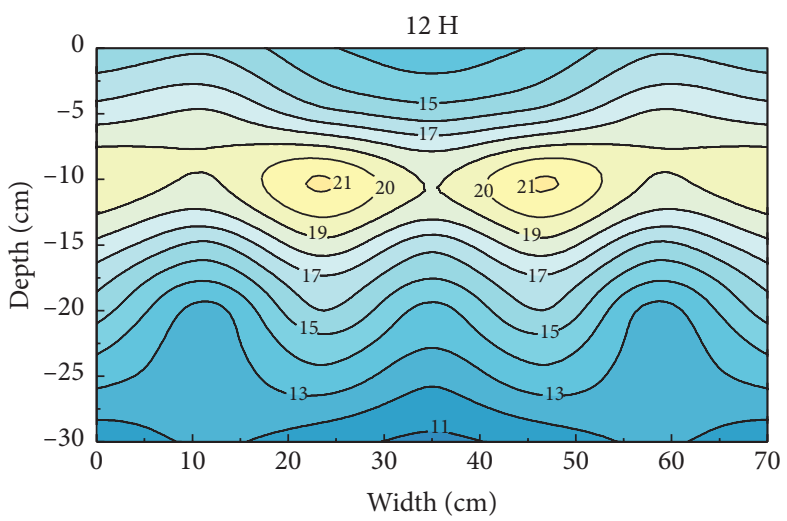

(h)

Figure 10: Continued. 


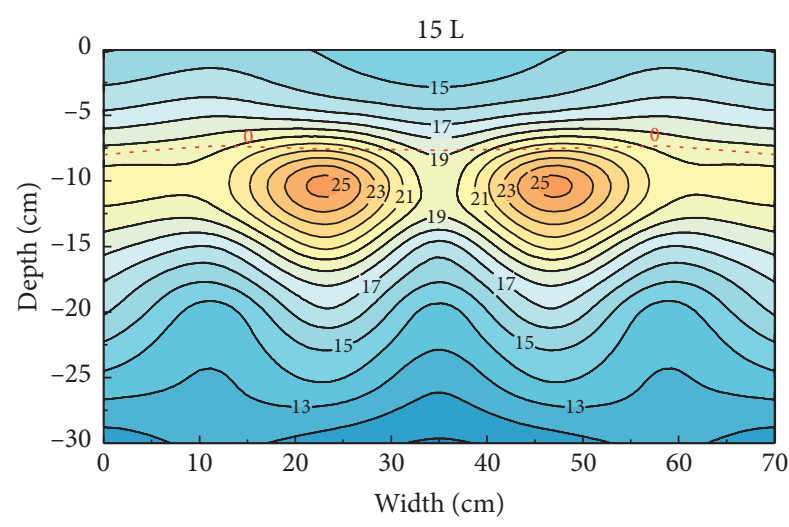

(i)

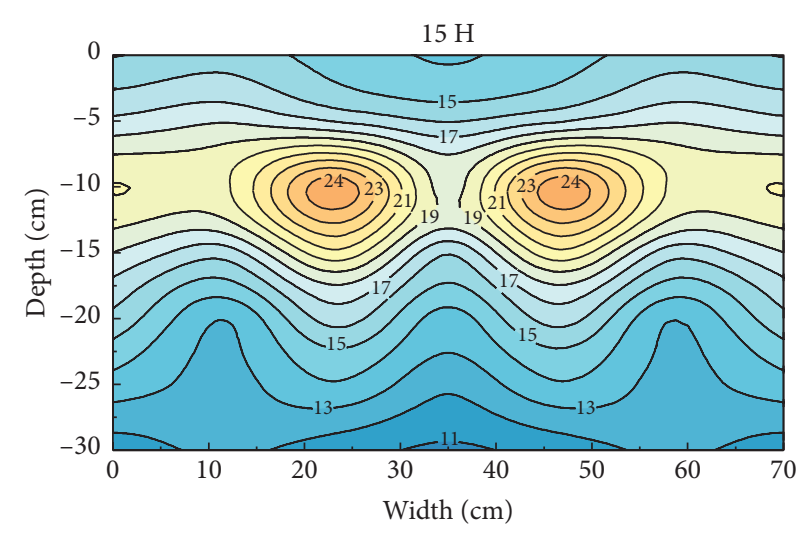

(j)

FIgURE 10: Variation of the moisture field at low and high temperature extremes at different freeze-thaw cycles.

conductivity during freezing is greater than that during thawing, making the accumulated cold capacity during freezing more than the amount of cold capacity dissipated during thawing $[30,31]$.

\subsection{Moisture Field in the Sample}

3.2.1. Freeze-Thaw Cycles. Figure 10 shows the variation of moisture field at the $\mathrm{H}$ and $\mathrm{L}$ time in different freeze-thaw cycles under the no-load condition. It can be seen that the water content in the soil sample changes slightly during the first freeze-thaw cycle, and the water distribution is relatively uniform and close to the initial water content. The moisture field in the soil sample changes obviously with the increasing freeze-thaw cycles. Especially after nine freezethaw cycles, two areas of moisture accumulation appear in the soil sample which has distance from the surface of $8-15 \mathrm{~cm}$ and symmetric distribution. Additionally, there is little change in the moisture accumulation area but a continuous increase in water content with increasing freeze-thaw cycles. For example, the maximum water content in the moisture accumulation area at $\mathrm{H}$ and $\mathrm{L}$ time is $25.5 \%$ and $26.1 \%$ after 15 freeze-thaw cycles, which increased by $15.5 \%$ and $16.1 \%$ from the initial water content, respectively. The reason for this phenomenon is that the temperature gradient drives the moisture migrated to the freezing front during freezing $[23,25]$. From Figure 10, it can be seen that the moisture accumulation area is close to the position of the $0^{\circ} \mathrm{C}$ line, which illustrates the relationship between the moisture migration area and temperature gradient. The moisture in the soil sample will flow downward under gravity during thawing, but the moisture flowing downwards is less than the migrating upward during the freezing due to the resistance effect of the soil; besides, since the soil is unsaturated in the model test, the moisture at the bottom of soil sample will also migrate upward under matric suction. By comparison, we found from Figure 10 that the moisture migrated upward during thawing is less than that during freezing. Therefore, during the freeze-thaw cycles, the moisture migrates towards the freezing front under various driving forces. Moreover, as the freeze-thaw cycles increase, the moisture migrating upward is more than that migrating downwards, which leads to the moisture gradually accumulating to form an accumulation area.

3.2.2. Freeze-Thaw Cycles under Dynamic Load. Figure 11 shows the variation of moisture field under dynamic load. It can be seen from the figure that the spatial distribution of water content in the soil sample is relatively uniform at the beginning of freeze-thaw. However, the water content significantly increases with the increasing freeze-thaw cycles, especially after nine freeze-thaw cycles. Three moisture accumulation areas appear in the soil sample: one is located below the vibration plate and the other two are located below the side of the vibration plate. Compared with Figure 10, it can be found that the locations of the moisture accumulation areas are lower under dynamic load than those under the noload condition, which is mainly due to the soil near the vibration plate being compacted by the load, and the moisture-holding capacity is reduced. For example, during freezing of the 9th freeze-thaw cycles, the area with water content greater than $15 \%$ appeared in the range of $10-25 \mathrm{~cm}$ from the soil surface below the vibrating base plate and the area with water content greater than $15 \%$ appeared in the range of $10-30 \mathrm{~cm}$ from the soil surface below the side of the vibrating base plate. During the freezing process of the 15th freeze-thaw cycle, the area with water content greater than $19 \%$ appeared in the range of $10-22.5 \mathrm{~cm}$ from the soil surface below the vibrating base plate and the area with water content greater than 19\% appeared in the range of $10-25 \mathrm{~cm}$ from the soil surface below the side of vibrating base plate. The variation in the water content and the range of the moisture accumulation area indicates that the moisture of the soil sample below the vibration plate tends to migrate upwards. The reason for this is that, on the one hand, the freeze-thaw cycle causes the moisture to migrate to the freezing front; on the other hand, the vibration load leads the adsorption force of the soil pores to increase $[32,33]$. 


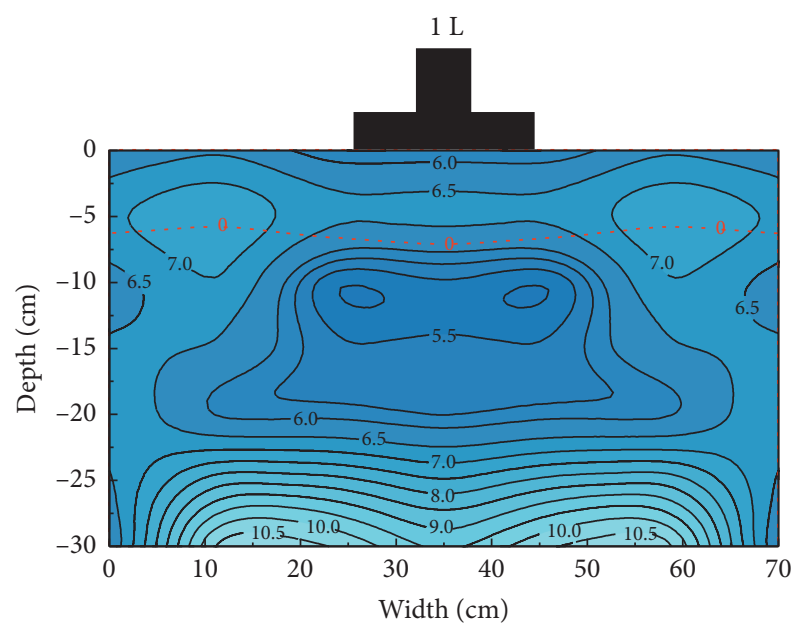

(a)

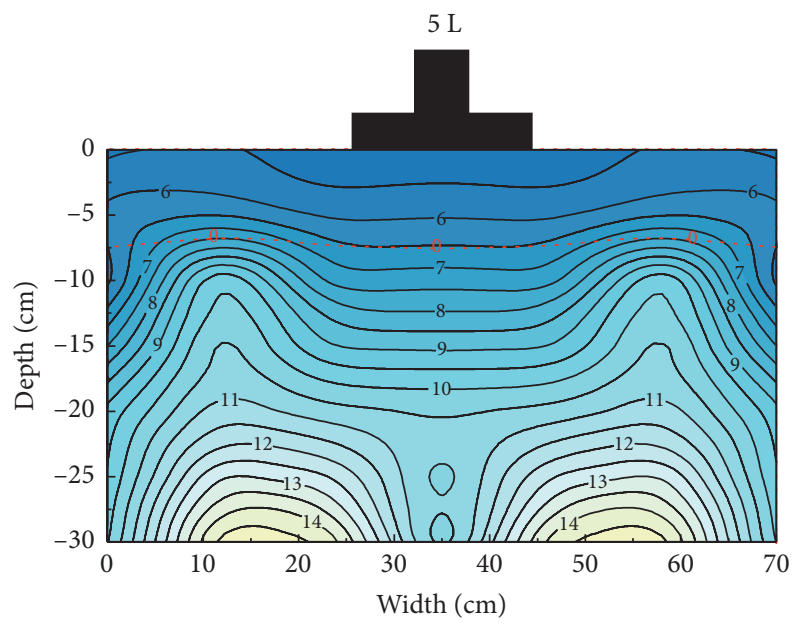

(c)

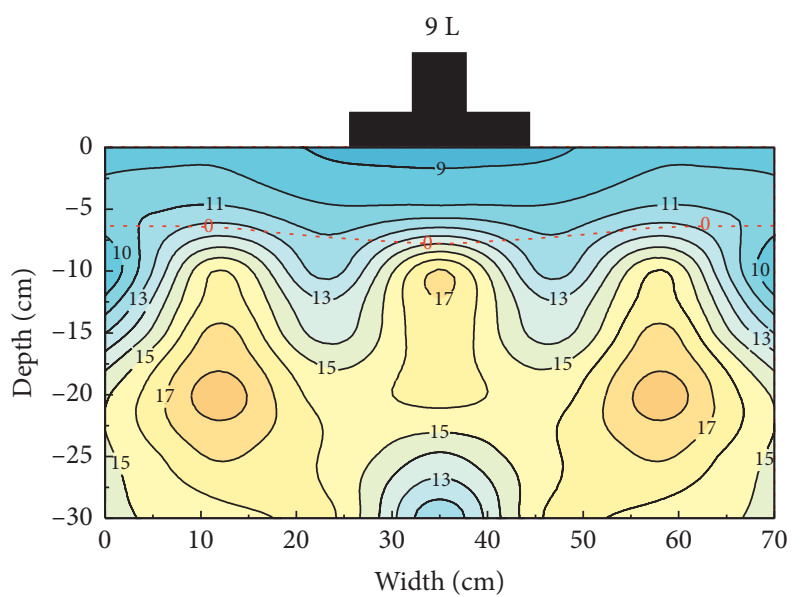

(e)

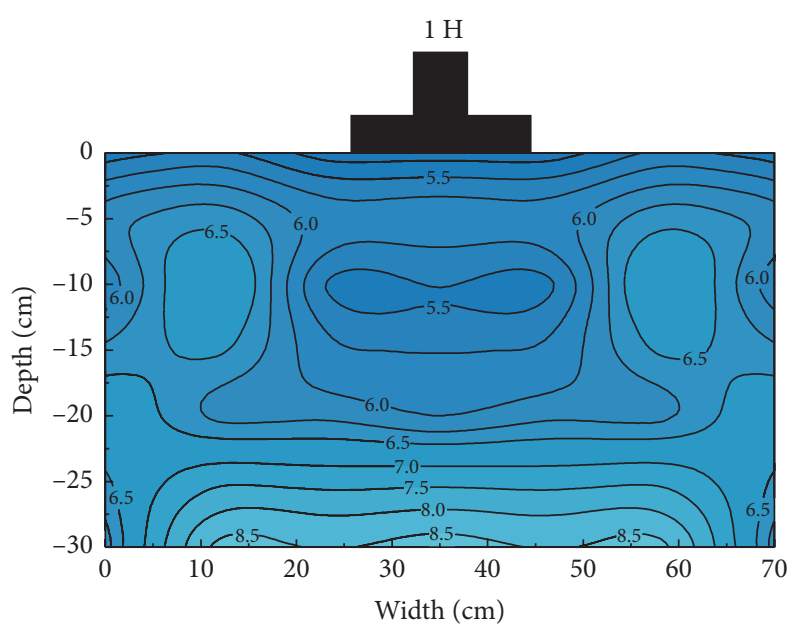

(b)

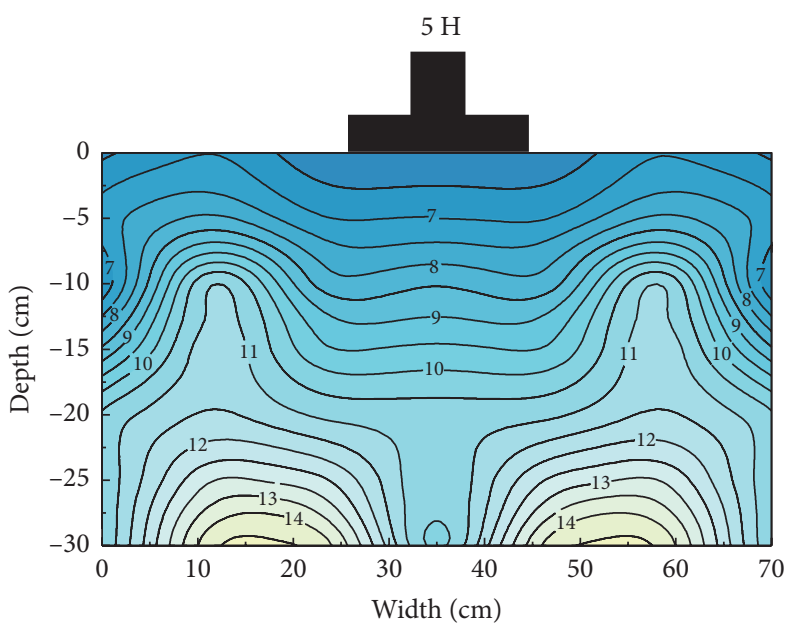

(d)

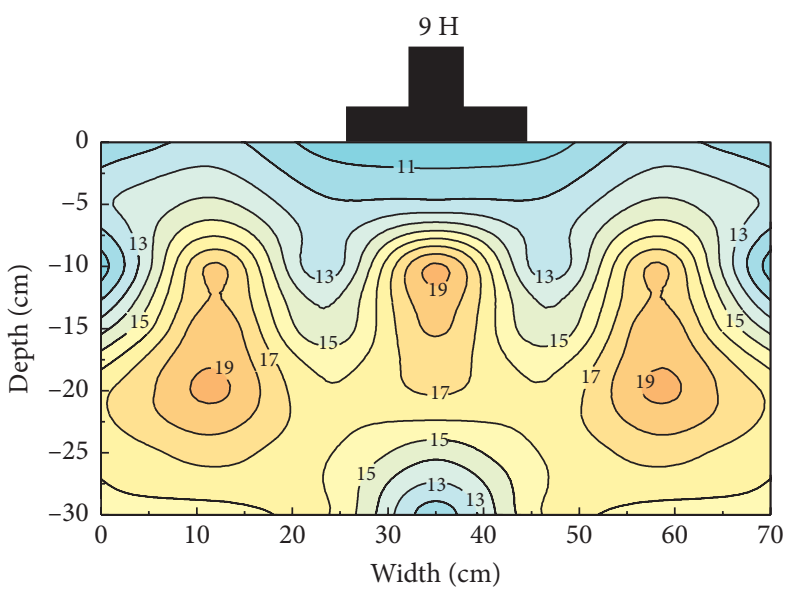

(f)

Figure 11: Continued. 


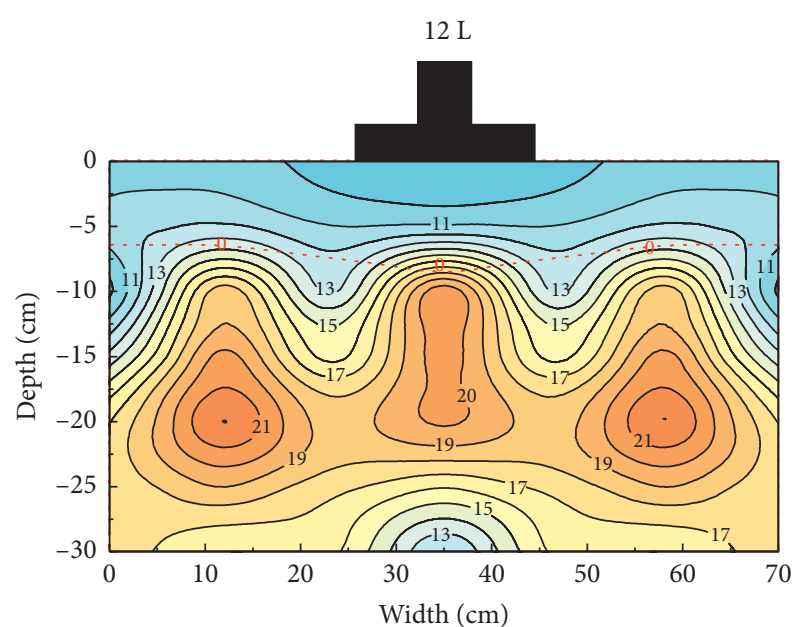

(g)

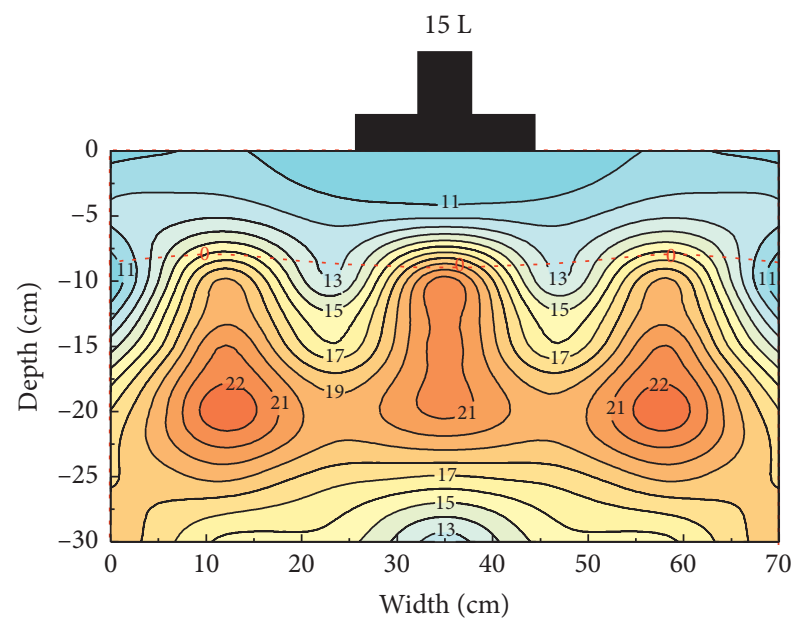

(i)

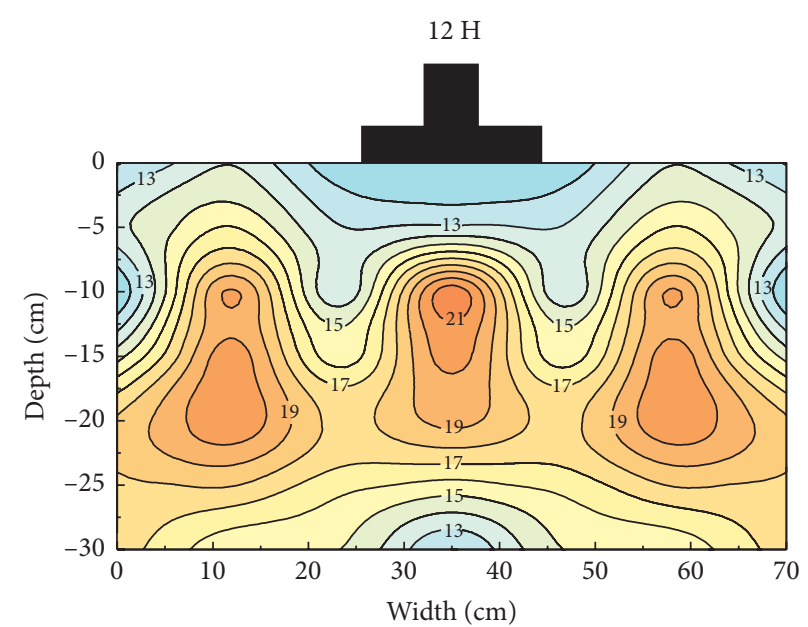

(h)

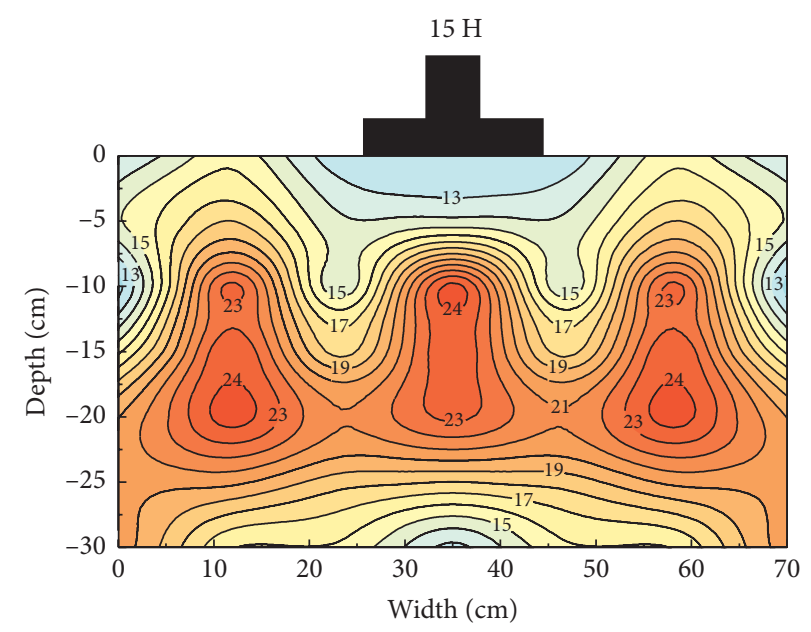

(j)

Figure 11: Variation of the moisture field at low and high temperature extremes under dynamic load and different freeze-thaw cycles.

Comparing the moisture field under the $\mathrm{L}$ and $\mathrm{H}$ time, Figure 11 shows that the difference of water content between freezing and thawing is slightly at the beginning of the freeze-thaw cycles. The difference gradually increases with the increase in freeze-thaw cycles. The reason for the variation is that when the ambient temperature is negative, the moisture in the soil migrates to the freezing front, leading to the reduction of water content in the middle of the soil sample. When the ambient temperature is positive temperature, the moisture in the soil under the vibration plate begins to move downwards and to both sides of the vibration plate due to the effect of dynamic load, which increases the water content in the middle of the sample. Besides, the dynamic load improves the adsorption force of the soil pores, which leads to the increase in the water content of the middle and upper parts of the soil sample. Compared with the moisture field under no load, it can be found that the water content of the moisture accumulation area during freezing is greater than that during thawing under the noload condition and the water content of the moisture accumulation area during freezing is less than during thawing under dynamic load condition, which indicates that the dynamic load improves the adsorption potential energy of the soil pores and significantly enhances the capillary moisture migration during thawing [34].

\section{Discussion}

There are three moisture accumulation areas in the soil sample for the dynamic load test, which is different from the no-load test. The formation of the three water accumulation areas under dynamic load is closely related to the internal stress field in the soil sample. Figure 12 shows the internal stress distribution of the soil under dynamic load. It can be seen that both the longitudinal stress and transverse stress decrease with the increasing depth. The longitudinal stress is mainly concentrated under the vibration plate, and the curves bulge vertically downward, while the transverse stress is distributed as the symmetric saddle. It can be seen from Figure 12 that the soil on both sides of the vibration plate is subjected to higher stresses so that the soil here is compressed and the porosity is reduced; the moisture is squeezed and migrates to the place with less stress. 


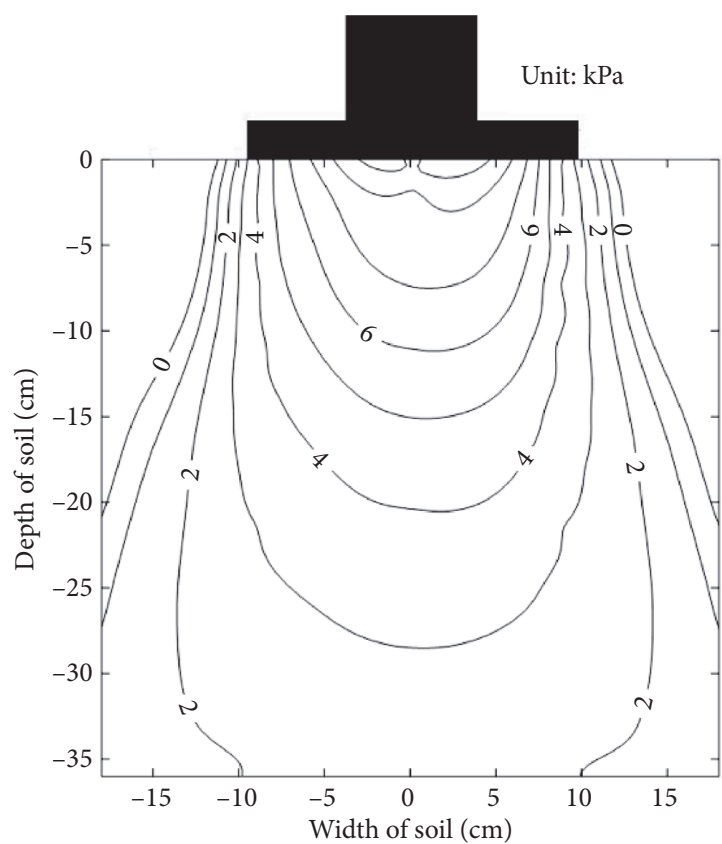

(a)

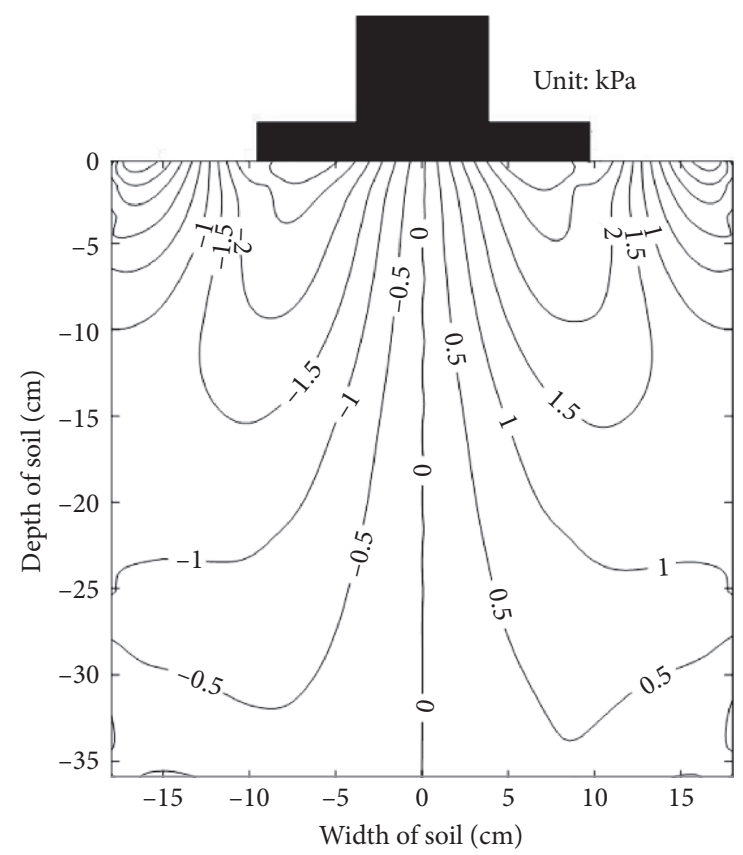

(b)

Figure 12: Longitudinal stress fields (a) and transverse stress (b) in soil under the dynamic load.

In Figures 10 and 11, there are two moisture accumulation areas under the no-load condition. In comparison, there are three moisture accumulation areas under dynamic load, which is also caused by the variation of porosity due to load [31-33]. The stress compresses the soil, resulting in the extrusion of moisture from the soil and migrates to surrounding soil that creates moisture accumulation areas. This is the reason why the moisture accumulation area increases to three when the dynamic load is applied.

\section{Conclusion}

Two model tests were carried out to study the influence of dynamic load on the temperature and moisture fields of the soil during the freeze-thaw cycling and obtained the following conclusions:

(1) The temperature of the soil shows periodic change with the ambient temperature, and the closer to the surface of the soil, the greater the variation amplitude of temperature. The temperature in the soil sample gradually decreases with the increase in freeze-thaw cycles, which is caused by the accumulation of cold capacity in the soil sample during the freeze-thaw cycles.

(2) The moisture gradually migrates upward and accumulates near the freezing front to form moisture accumulation areas with the increasing freeze-thaw cycles.

(3) The dynamic load compacts the soil near the vibration plate that the position of moisture accumulation areas is lower than that under the no-load condition. Under the dynamic load, longitudinal and transverse stresses are generated in the soil sample, which causes three water aggregation areas to be formed, and the water content increases with the increase in freeze-thaw cycles in these areas.

(4) The water content of the moisture accumulation areas during freezing is greater than that during thawing under the no-load condition, while the water content of the moisture accumulation areas during the freezing period is less than that during thawing under dynamic load. This indicates that the dynamic load improves the adsorption potential energy of the soil pores and significantly enhances the capillary moisture migration during thawing.

\section{Data Availability}

The data used to support the findings of this study are included within the article.

\section{Conflicts of Interest}

The authors declare that they have no conflicts of interest.

\section{Acknowledgments}

This work was supported by the National Natural Science Foundation of China (No. 41630636).

\section{References}

[1] Y. Zhou, D. Guo, G. Qiu, G. Chen, and S. Shu, Geocryology in China, Science Press, Beijing, China, 2000.

[2] Z. Zhang, W. Ma, and J. Qi, "Structure evolution and mechanism of engineering properties change of soils under effect of freeze-thaw cycle," Journal of Jilin University (Earth Science Edition), vol. 43, no. 6, pp. 1904-1914, 2013. 
[3] J. Qi, P. A. Vermeer, and G. Cheng, "A review of the influence of freeze-thaw cycles on soil geotechnical properties," Permafrost and Periglacial Processes, vol. 17, no. 3, pp. 245-252, 2006.

[4] E. J. Chamberlain and A. J. Gow, "Effect of freezing and thawing on the permeability and structure of soils," Developments in Geotechnical Engineering, vol. 13, no. 1-4, pp. 73-92, 1979.

[5] D. R. Ingles, "Particle sorting and stone migration by freezing and thawing," Science, vol. 143, pp. 1616-1617, 1965.

[6] L. Fang, J. Qi, and W. Ma, "Freeze-thaw induced changes in soil structure and its relationship with variations in strength," Journal of Glaciology and Geocryology, vol. 34, no. 2, pp. 435-440, 2012.

[7] J. Qi, J. Zhang, and Y. Zhu, "Influence of freezing-thawing on soil structure and its soil mechanices significance," Chinese Journal of Rock Mechanies and Engineering, vol. 22, no. S2, pp. 2690-2694, 2003.

[8] N. Wang, Y. Mao, D. Zhang, G. Li, and Y. Mu, "Influence of freezing-thawing cycles on loess slope in seasonal frozen soil regions," Highway traffic science and technology, vol. 4, pp. 79-84, 2011.

[9] X. Xu, J. Wang, and L. Zhang, Physics of Frozen Soils, Science Press, Beijing, China, 2001.

[10] T. Zhang and P. Yang, "Effects of unilateralist freezing on the moisture migration of soil," Journal of Nanjing Forestry University (Natural Science Edition), vol. 37, no. 1, pp. 117-121, 2013.

[11] J. M. Konrad and R. Morgenstern, "A mechanistic theory of ice lens formation in fine-grained soils," Canadian Geotechnical Journal, vol. 17, pp. 476-486, 1980.

[12] R. R. Gilpin, "A model for the prediction of ice tensing and frost heave in soils," Water Resource Research, vol. 21, pp. 281-296, 1985.

[13] R. J. Hanks, "Water vapor transfer in dry soil," Soil Science Society of America Journal, vol. 22, no. 5, pp. 372-374, 1958.

[14] X. Chen and J. Liu, Frost Action of Soil and Foundation Engineering, Science Press, Beijing, China, 2006.

[15] H. Zhang, T. Wang, and Y. Luo, "Experimental study on moisture migration of unsaturated loess under freezing effect," Journal of Engineering Geology, vol. 23, no. 1, pp. 72-77, 2015.

[16] J. Lu, M. Zhang, X. Zhang, and R. Yan, "Experimental study on the unfrozen water content and the freezing temperature during freezing and thawing processes," Chinese Journal of Rock Mechanics and Engineering, vol. 36, no. 7, pp. 1803-1812, 2017.

[17] H. Wei, J. Zhou, C. Wei, and P. Chen, "Experimental study of water migration in saturated freezing silty soil," Rock and Soil Mechanics, vol. 37, no. 9, pp. 2547-2552, 2016.

[18] F. Ming and D. Li, "Characteristics of moisture migration in freezing silty clay under the pressure," Journal of Chang'an University (Natural Science Edition), vol. 35, no. 3, pp. 67-73, 2015.

[19] T. Wang and H. Lu, "Moisture migration in unsaturated loess considering temperature effect," Rock and Soil Mechanics, vol. 25, no. 7, pp. 1081-1084, 2004.

[20] L. Huang, Y. Shen, X. Huang, B. He, and X. Zhang, "Experimental study on force and deformation of soil during unidirectional frost heave under different paths," Chinese Journal of Rock Mechanics and Engineering, vol. 38, no. S2, pp. 3870-3882, 2019.

[21] G. Zhao, X. Tao, and B. Liu, "Experimental research on water migration in remolded soil during freezing and thawing process," Journal of Central South University (Science and Technology), vol. 40, no. 2, pp. 519-525, 2009.

[22] G. Zhao, X. Tao, and B. Liu, "Experimental research on water migration in distributed soil during freezing and thawing process," Chinese Journal of Geotechnical Engineering, vol. 31, no. 12, pp. 1952-1957, 2009.

[23] L. Zhang, W. Ma, C. Yang, and C. Yuan, "Investigation of the pore water pressures of coarse-grained sandy soil during open-system step-freezing and thawing tests," Engineering Geology, vol. 181, pp. 233-248, 2014.

[24] Z. Zhou, W. Ma, S. Zhang, Y. Mu, and G. Li, "Effect of freezethaw cycles in mechanical behaviors of frozen loess," Cold Regions Science and Technology, vol. 146, pp. 9-18, 2018.

[25] F. Wang, S. Tang, and H. Wang, "Review of research on soil mobility in seasonally frozen area," Journal of Irrigation and Drainage, vol. 39, no. S1, pp. 51-55, 2020.

[26] GB/T50123-1999, The Standard of Chinese Soil Test Method, China Water \& Power Press, Beijing, China, 2009.

[27] D. Xiao, W. Ma, S. Zhao, Z. Zhang, W. Feng, and L. Zhang, "Research on pore water pressure and moisture content in soil subjected to freeze-thaw cycles and loading action by model test," Chinese Journal of Rock Mechanics and Engineering, vol. 36, no. 4, pp. 977-986, 2017.

[28] M. Qiu, Study on Post-Construction Settlement of Road under Traffic Load, Zhejiang University, Hangzhou, China, 2011.

[29] M. Shen, Z. Zhou, and S. Zhang, "Effect of stress path on mechanical behaviours of frozen subgrade soil," Road Materials and Pavement Design, 2020.

[30] Z. Zhou, W. Ma, S. Zhang, Y. Mu, and G. Li, "Experimental investigation of the path-dependent strength and deformation behaviours of frozen loess," Engineering Geology, vol. 265, Article ID 105449, 2020.

[31] N. Li, B. Chen, and F. Chen, "Heat-moisture-deformation coupled for composite foundation in cold zone," China Civil Engineering Journal, vol. 36, no. 10, pp. 66-71, 2003.

[32] X. Xiao, X. Feng, L. Lin, B. Jiang, and Z. Feng, “An experimental research of vibration pore water pressure of remolded silt under low confining pressure: A case from Chengbei sea area," Marine Geology \& Quaternary Geology, vol. 40, no. 4, pp. 214-222, 2020.

[33] D. Xiao, Model Test Study on the Moisture, Pore Water Pressure Subjected to the Freeze-Thaw Cycle and Load Actions, University of Chinese Academy of Sciences, Beijing, China, 2017.

[34] R. D. Jackson, "Water vapor diffusion in relatively dry soil: I. Theoretical considerations and sorption experiments," Soil Science Society of America Journal, vol. 28, no. 2, pp. 172-176, 1964. 